\title{
Experimental Validation of Mathematical Models for Diesel-Electric Shunting Locomotive Traction Curve
}

\author{
Halil Deveci ${ }^{1,2}$ \\ ${ }^{I}$ R\&D Engineer, R\&D Department, Turkish Railway Vehicles Industry Inc., Eskişehir, Turkey \\ ${ }^{2}$ Ph.D. Candidate, Electrical Engineering, Graduate School, Istanbul Technical University, Istanbul, Turkey
}

\begin{abstract}
In this study, dynamical modelling and calculation of the traction curve of a shunting locomotive which have been designed and produced by TURASAS (Turkish Railway Vehicles Industry Inc.) (Formerly known as TULOMSAS (Turkish Locomotive \& Engine Industry Inc.)) have been done. The longitudinal dynamics of the vehicle are calculated to determine its hauling capacity. The results are compared with the experimental results to see the locomotive has enough performance in terms of traction force and slippage. The experimental results show that the constructed model is calculating the tractive effort accurately for these types of shunting locomotives. The same model structure is tried with high-speed train parameters and the results are examined. The model has been changed according to calculate the traction curve of a high-speed train by using Muller Formula, and the obtained traction curve has been optimized by changing the weight distribution of the train between the driven and non-driven axis. Matlab-Simulink is used to create the proposed models and to realize the simulations. In this way, a comparison is obtained, and the key points are emphasized when calculating the traction curves of different types of railway vehicles. The results show that these types of mathematical models can play an important role to determine the specifications of the vehicles, and to configure sub-systems used in vehicles.
\end{abstract}

Keywords: Traction Curves, Diesel Electric, Shunting Locomotive, Locomotive, High Speed Trains

\section{I.INTRODUCTION}

It is known that the main performances of the heavy haul locomotives are based on the attributes of their power supply and on their electro-traction transmission characteristics. Hence, these features describe the tractive and braking capabilities of a rail vehicle dependant on the train speed and the load being hauled [1]. However, the magnitude of the tractive effort is also dependent on the torque transmitted to the wheels and the adhesion between rail and wheel. There is a certain limit to transmit the power to the wheels effectively and to increase the acceleration of the vehicle without getting caught by wheel-slip [2]. It is important to determine all of these parameters accurately to calculate the traction curves and to create realistic models of railway vehicles. In this work, a model is proposed to calculate the traction curve of the locomotives instantenously. In order to validate the obtained curves and detect the traction performances of the produced locomotive experimental validations have been executed.

\section{LITERATURE REVIEW}

There are many studies in the literature which is studying performance, efficiency, and cost-benefit analysis of railway vehicles. To examine these specifications properly different types of dynamical models are created and used by researchers. Most of these studies are focus on reducing emissions, energy storage systems, and energy efficiency lately. For making these goals available there are several methods and many different systems. Regenerative braking is one of the widely studying areas. Boizumeau JR and Leguay studied the latest regenerative braking technologies [3]. Public railway transportation companies are working to reduce their emissions and maintain their sustainability [4]. Energy efficiency can also be achieved by optimizing the drive. Miyatake et al. [5,6] studied the optimization of the speed profile of a train. Hybrid railway vehicles are also significant for low emissions and high efficiency. Henning et al. studied hybrid light railway vehicles [7]. This article is aiming to construct specific dynamical models to calculate the traction curves of different types of railway vehicles. One of the most important parameters to determine the traction curve of a railway vehicle is adhesion force, and it is often determined experimentally. Onat and Votr used an optimization technique and a test stand to find optimum adhesion parameters for a tram [8]. 


\section{III.RESEARCH METHODOLOGY}

In this research calculation of traction curve of the DE10000K Diesel Electric Locomotive have been done according to Curtiss-Kniffler and other required equations given below. Matlab-Simulink is used for the simulations. Performance calculations and simulations under different resistances are also realized and compared with each other. Finally, after the production stage is over, comparision of the simulation outputs with experimental results has been done. The parameters that needed for the simulation - of some physhical phenomenions like slippage - are optimized according to test results.

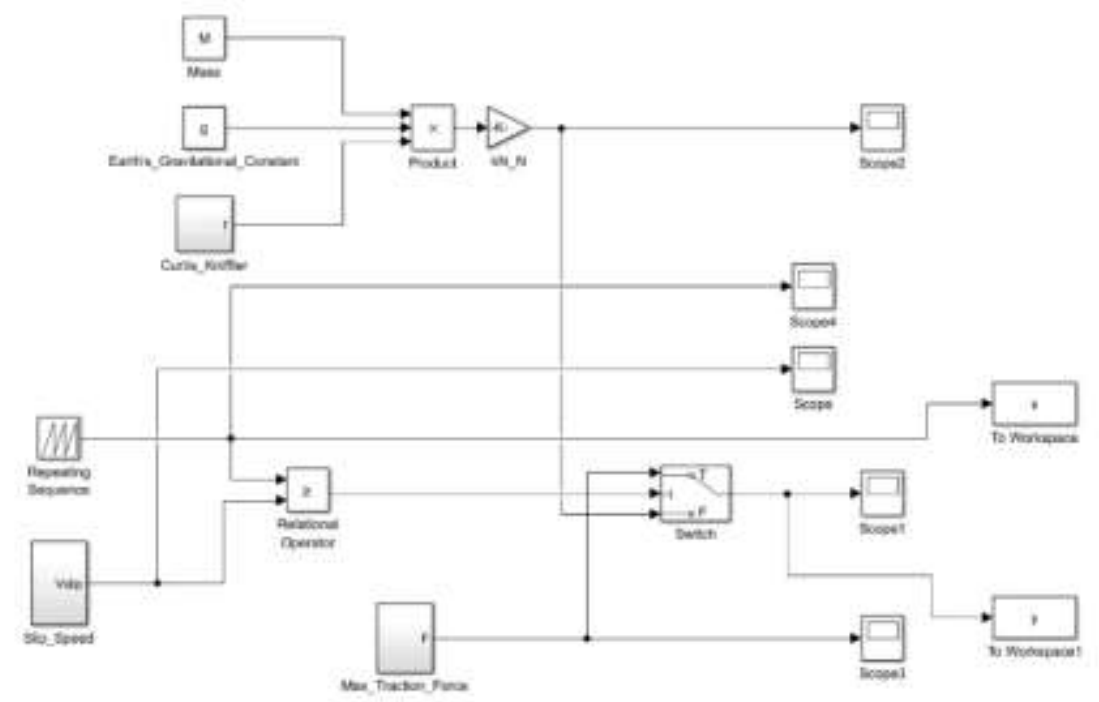

Fig. 1 Block diagram of traction curve calculator model (simulink screenshot).

\section{SIMULATION FINDINGS AND RESULTS}

\section{A. Diesel Electric Shunting Locomotive Traction Curve Simulation}

Constructed traction curve calculator model to estimate the traction curve of the locomotive having $839 \mathrm{~kW}$ diesel engine which is being one of the DE10000K series designed and produced 3 pieces (In total, 7 locomotives are delivered to the customer in conjunction with the 4 pieces locomotive having $571 \mathrm{~kW}$ diesel engine) for KARDEMİR (Karabük Iron Steel Industry Trade\&Co. Inc.) by the TURASAS is given below.

The formulas that used in the model has been given [9]:

$F_{1}=\frac{P}{V}$

$f=0,161+\frac{7,5}{44+V}$ (Curtius-Kniffler Formula)

$V_{\text {slip }}=0,2224 \cdot P-8 \cdot m_{\text {loko }}+\sqrt{64 \cdot m_{\text {loko }}^{2}+0,05 \cdot P^{2}}$

$F_{2}=m \cdot g \cdot f$

And the formulas that are not used in the model but used in the calculations in the next chapters:

$F_{R}=A+B . V+C . V^{2}$ (Davis Formula)

Coefficients in the Davis Formula are experimental parameters and there are many different revised versions of them in the literature. To determine the exact movement of the railway vehicle in the longitudinal direction, we can combine the Newton equations with train resistances and thus we obtain Lomonossof's equation [9]:

$M_{e} \frac{d^{2} s}{d t^{2}}=F-M g \sin (\alpha)-F_{R}$

The forces affecting the vehicle can be understood well by Figure-2. $M_{e}$ is the effective mass of the vehicle which is a corrected term with the addition of the rotational masses in the vehicle. 


\section{International Advanced Research Journal in Science, Engineering and Technology}

Vol. 8, Issue 7 , July 2021

DOI: 10.17148/IARJSET.2021.8701

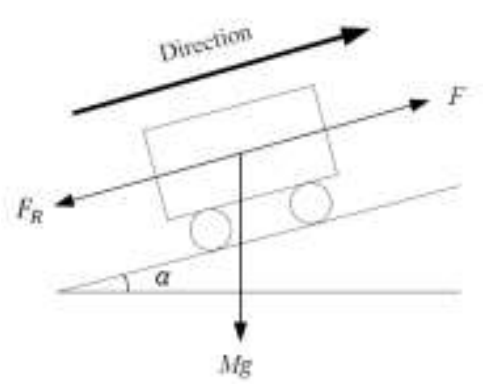

Fig. 2 Forces on a moving railway vehicle

$\mathrm{P}$ is the traction power, $\mathrm{V}$ is the locomotive speed, $\mathrm{F}$ is the traction force, $\mathrm{f}$ is the adherence coefficient, $V_{\text {slip }}$ is the slip speed $m_{\text {loko }}$ is the mass of the locomotive and $F_{R}$ is the total braking force here. Basically, the simulation chooses that which curve will determine the traction curve according to the locomotive speed. The traction curve is calculated by increasing the locomotive speed fictitiously with an appropriate ramp via repeating sequence block. The calculated traction curve for DE10000K locomotive is given below in Figure-3.

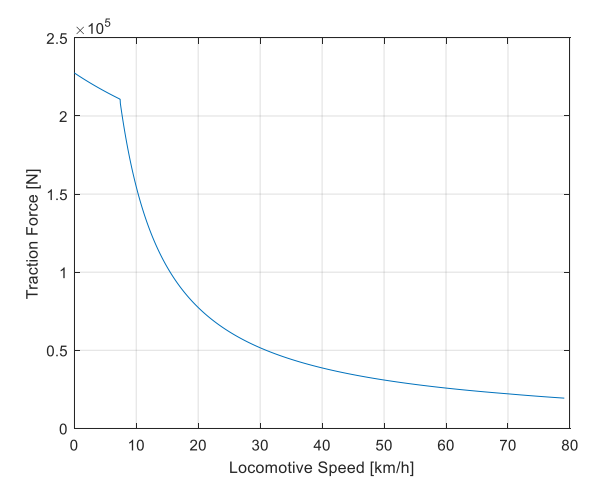

Fig. 3 Calculated traction curve for the DE10000K shunting locomotive.

The parameters of the model are given below in Figure-4. The power transmitted to the wheels is assumed as $430 \mathrm{~kW}$ here. Diesel motor output is $839 \mathrm{~kW}$ as mentioned in earlier sections. $85 \mathrm{~kW}$ is separated to drive the hydrostatics pumps of the cooling system and the air compressor. Therefore there is $754 \mathrm{~kW}$ mechanical power as an input of the alternator. There is also extra equipment consuming $25 \mathrm{~kW}$ in total. They are actually, a charging alternator and traction motor blower coupled to the same shaft with the alternator. So the power converted to electrical energy would be approximately $730 \mathrm{~kW}$ at least. In the worst scenario, we would have 0,6 efficiency for the rest of the powertrain system (alternator, traction converter, traction motors, gears) in total. Equation (7) shows the total efficiency of the powertrain system. Hence, we obtain approximately $430 \mathrm{~kW}$ at the wheels. The efficiency of the powertrain system and the power at wheels in practice would be probably better than this, however, to be sure that we will overcome the performance requirements, we have to evaluate the worst scenarios.

$$
\eta_{\text {total }}=\eta_{\text {alternator }} \cdot \eta_{\text {converter }} \cdot \eta_{\text {tractionmotor }} \cdot \eta_{\text {gearbox }} \cong 0,6
$$


Vol. 8, Issue 7 , July 2021

DOI: 10.17148/IARJSET.2021.8701

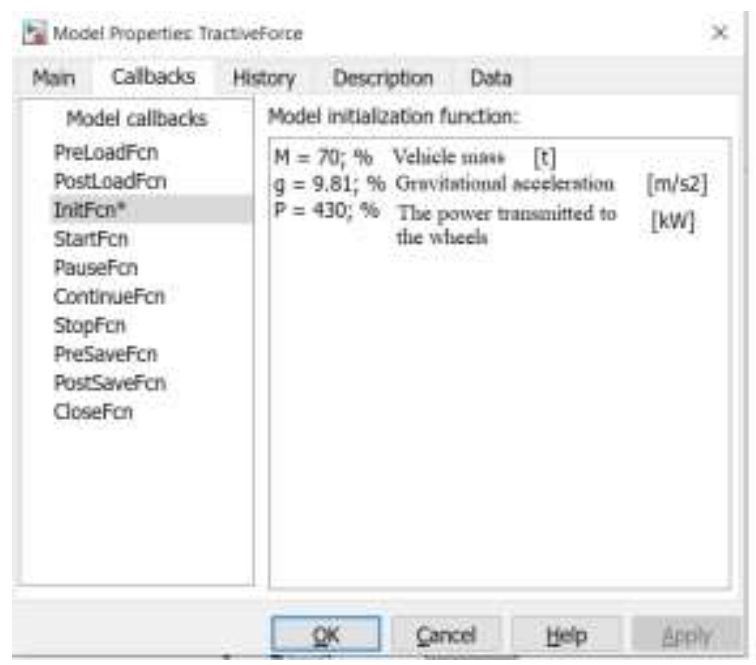

Fig. 4 Required parameters for calculation of traction curve of the DE10000K shunting locomotive.

The same curve could be obtained via the addition of two curves for this simulation. You can see the same curve, below of the intersection of two curves. The intersection point corresponds to slip speed in the $\mathrm{x}$-axis as we can conclude. We should not forget that the curve obtained with this method is an idealized curve which is determining the limit for tractive effort. In the real traction curve of the locomotive, the characteristics of the traction system also play an important role. Hence, the left side of the slip speed in the curve should be drawn appropriately to the structure of the traction system. In addition, continuous traction effort can only be possible around forces that correspond to the slip speed [10].

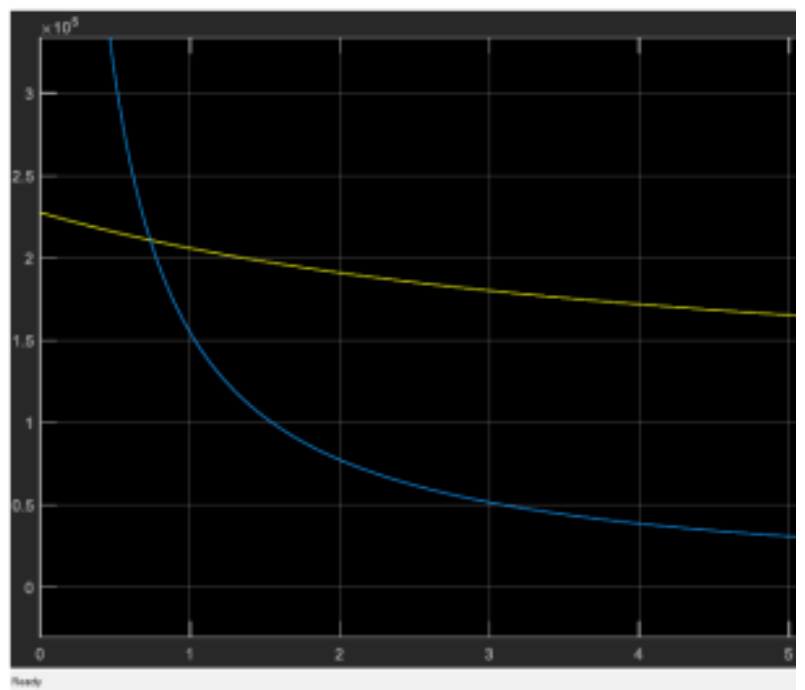

Fig. 5 An alternative method to find the slip speed without formula (x-axis [speed/10km/h])

Apparently, these curves could be merged appropriately via comparison blocks and the first curve could be obtained. We can see that slip speed is consistent with the calculated value by the given empirical formula. Now, the $\mathrm{x}$-axis is seen as a time axis. But because of we define the speed by the value of the repeating sequence block (which is defined for 10 $\mathrm{km} / \mathrm{h}$ increment each second), we can see the obtained curves are found identical by two methods.

This increment in speed is just hypothetical. Even if it is not possible in a real system, this approximation is serving to the aim of the simulation. This method is adopted because it is more practical than plot the force-speed curve via command at each time. This path will be followed also in the next simulations in this work.

Major advantages of the constructed model are given below:

1) It can be used for the calculation of the traction curves of the other locomotives or vehicles with its parametrical structure.

2) It can be used for further analysis with modeling of the loads with the help of the Davis formula.

In this model, the vehicle speed is an input which is defined by user via repeating sequence block. With some revisions, it can be obtained by taking the integral of the acceleration which is calculated by the Newton's Second Law, and can be 
Vol. 8, Issue 7 , July 2021

DOI: 10.17148/IARJSET.2021.8701

use to obtain the realized traction force with a feedback. (Implementation of the train resistances to the model needs vehicle speed to obtain the air resistance.) In this new type model, the traction force demanded by driver will be an input, and the vehicle speed will be an output. With the usage of the output as a feedback, traction force will be calculated. Thus, with the development of the constructed model, a real driving simulation can be done [11]. This type of model will examine in further studies. It is crucial to determine the parameters correctly in these types of complex models [12]. However; in practice, these parameters are frequently determined experimentally [13].

\section{B. Comparison of the Traction Curve Obtained Via Model with Experimental Results and Calculations Without \\ Dynamical Model}

The parameters read from the HMI (Human Machine Interface) screen during the tests of DE10000K locomotive has given below. A Co-Co locomotive DE24000 has coupled to the DE10000K and get brake to increase the load of the testing locomotive. It is important to determine the tractive effort as far as precisely, and with an acceptable cost [14]. Furthermore, with the help of these tests, slip-skid algorithms has been optimized. If these screen views are examined carefully, it can be seen that the calculation of the traction curve has been done very precisely by the proposed model.

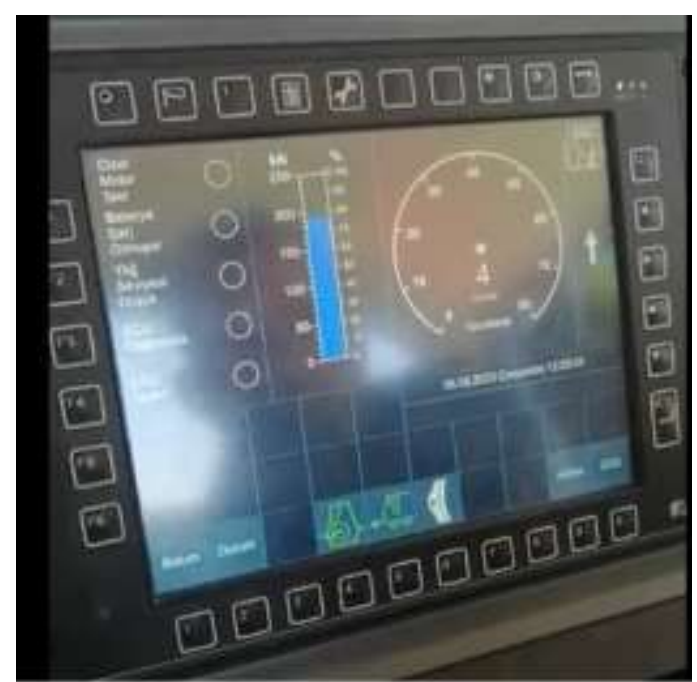

Fig. 6 Traction power demand, real traction force affecting the vehicle, and locomotive speed values which are seen from the screen during tests.

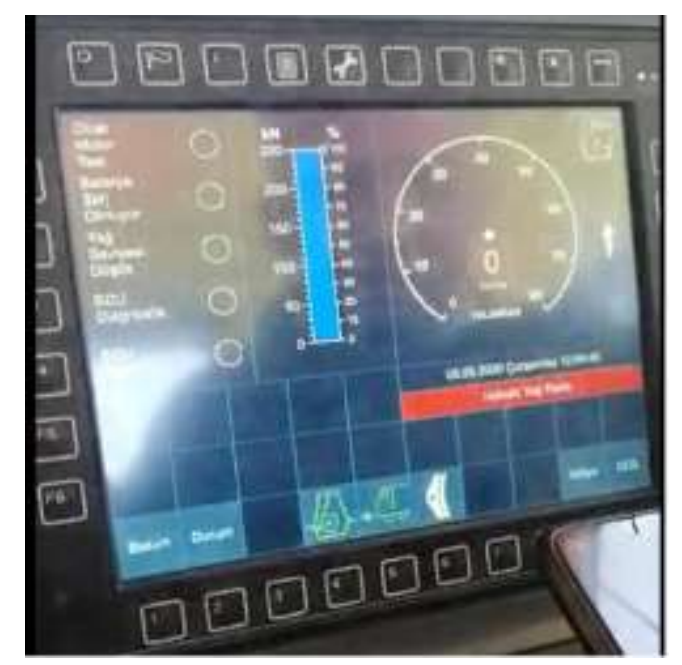

Fig. 7 Traction power demand, real traction force affecting the vehicle, and locomotive speed values which are seen from the screen during tests (Because of the braking force of the other locomotives is too much, DE10000K is not moving at this moment). 


\section{International Advanced Research Journal in Science, Engineering and Technology}

Vol. 8, Issue 7 , July 2021

DOI: 10.17148/IARJSET.2021.8701

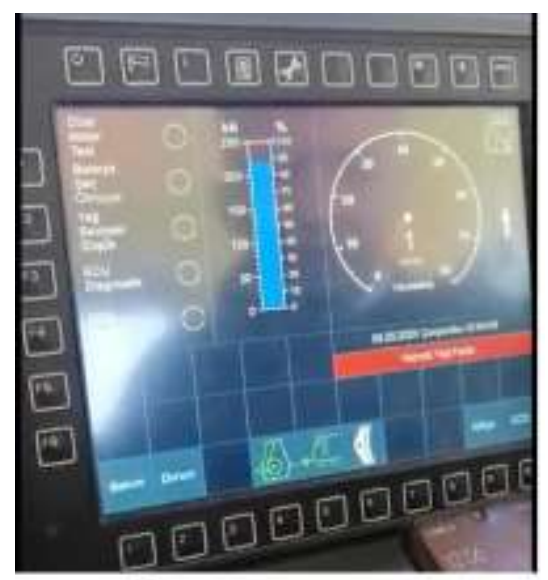

Fig. 8 Traction power demand, real traction force affecting the vehicle, and locomotive speed values which are seen from the screen during tests (It can be seen from the HMI that the traction force has overcome the train resistance and the locomotive is starting to move with a force more than $200 \mathrm{kN}$ ).

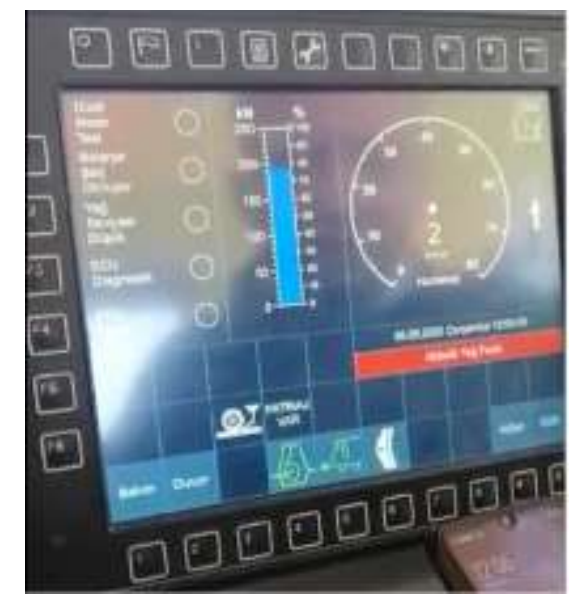

Fig. 9 Traction power demand, real traction force affecting the vehicle, and locomotive speed values which are seen from the screen during tests (It can be seen from the HMI that the the locomotive is detecting the slipping instantaneously).

Furthermore, load calculations for this locomotive which is obtained via Davis formula is used[15,16]. Despite in lower speeds first and second terms are dominant, in higher speeds wind resistance becomes prominent. However, these calculations and graphics are obtained via static formulas and an effective dynamical model is not been established. For this reason, the details about these calculations are not given at this paper. For further studies, it is aimed to expand the models which created in Matlab-Simulink and planned to realize more extensive studies like energy efficiency and energy storage systems. For instance Yang et al. studied exploit from the braking force via supercapacitor based energy storage systems in light railway vehicles. [17]. Frilli et al. studied energetic optimization of regenerative braking for high speed railway systems [18]. It can be seen that these types of mathematical models which we lay the base to construct can create significant inputs to the studies like theirs. Traction and load curves of the DE10000K locomotive under different conditions are given below. The worst scenarios are taken into account and the adherence limit is calculated lower than before. 


\section{International Advanced Research Journal in Science, Engineering and Technology}

Vol. 8, Issue 7, July 2021

DOI: 10.17148/IARJSET.2021.8701

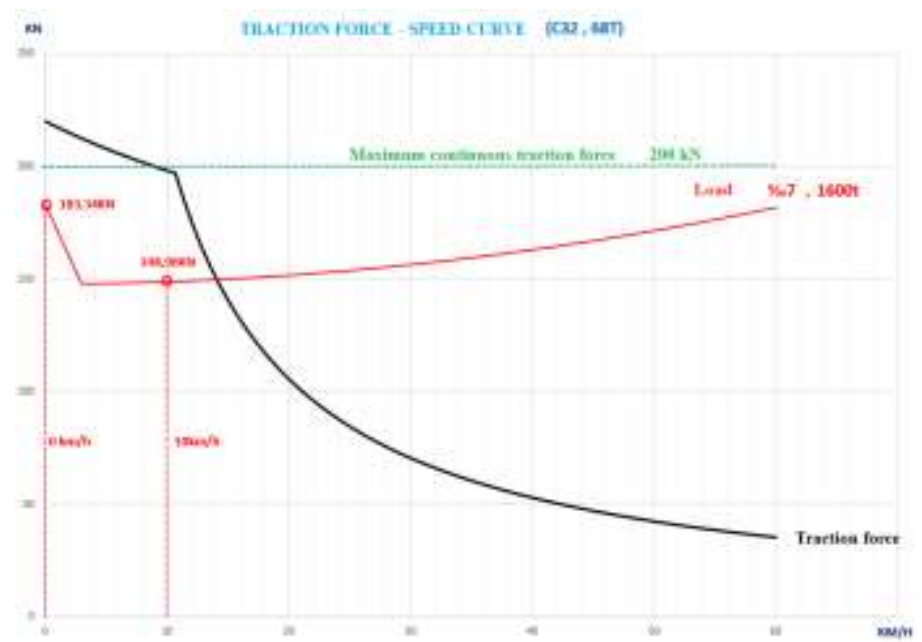

Fig. 10 Traction curve and load curve togerher (1600 t load, \% 0,7 slope) (first movement acceleration $0,2 \mathrm{~m} / \mathrm{s}^{2}$, additional rotational mass factor for train 0,06$)$.

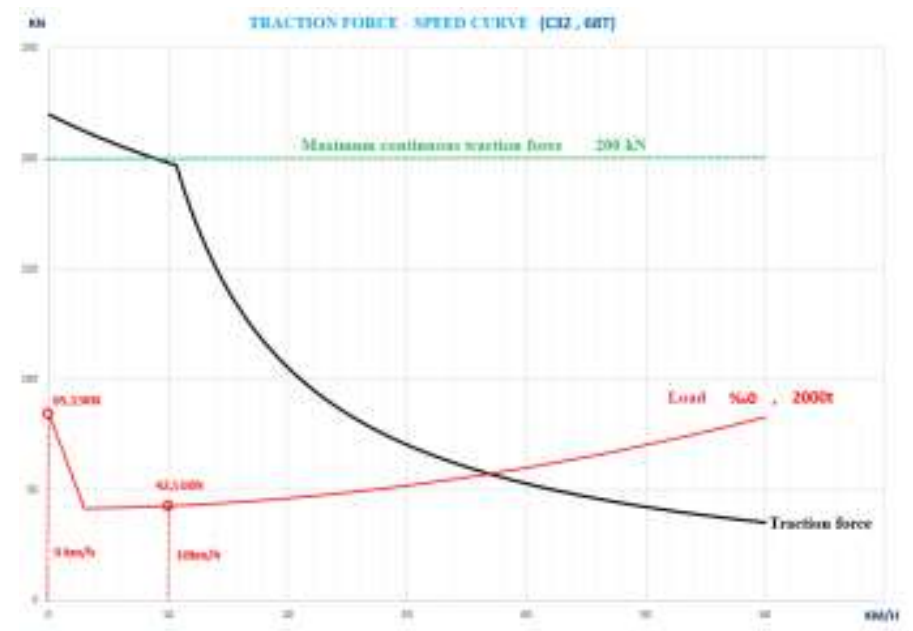

Fig. 11 Traction curve and load curve togerher (2000 t load, \% 0 slope) (first movement acceleration $0,2 \mathrm{~m} / \mathrm{s}^{2}$, rotational mass factor for train 0,06).

\section{High Speed Train Traction Curve Simulation}

When the same formula is implemented to the hst (high speed train) set the slip curve would be much higher than expected. This is caused from Curtis-Kniffler formula is not exactly valid for the systems like hst. Therefore, this part of the model has to be changed.

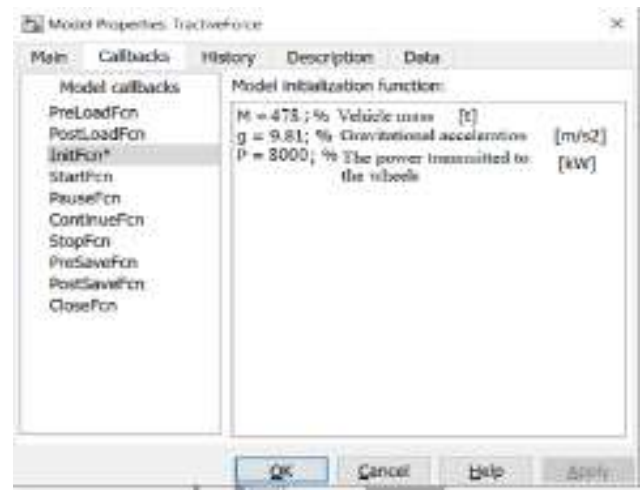

Fig. 12 The parameters of a hst to calculate the traction curve. 


\section{DOI: 10.17148/IARJSET.2021.8701}

To obtain the traction curves of high speed trains precisely, the Muller Formula should be used [18].

$\mu=\frac{\mu_{0}}{1+k_{\text {muller }}+x_{k m h}}$

Furthermore, for this formula to be valid in saturations, it should be multiplicated by a coefficient $\mathrm{k}_{m}$. To model the effect of the limited wheel-rail adhesion along the line, further saturations is introduced. Especially; traction force $\mathrm{T}_{T}$ and breaking force $\mathrm{T}_{B}$ which can be expressed as a function of adhesion coefficient $\mu$ can be found according to given formula: $T_{T} \leq T_{\text {Tmax }}=k_{m} m g \mu$

$\mathrm{T}_{B} \geq \mathrm{T}_{\text {Bmax }}=-\mathrm{mg} \mu$

The coefficient $\mathrm{k}_{m}$ here is the ratio between the verticle load affecting the axles and the total weight of the train. This coefficient can take different values. For a hypothetical high speed train set two different graphics are obtained for two different values of $\mathrm{k}_{m}$.

Let's examine a high speed train which has a configuration 32 axles in total, and 16 of them driven by a traction motor. With the assumption of driven and non-driven axles are taken the same verticle force - which means that they are carrying equal mass - we can take $\mathrm{k}_{m}$ value 0,5 we obtain a traction curve given below:

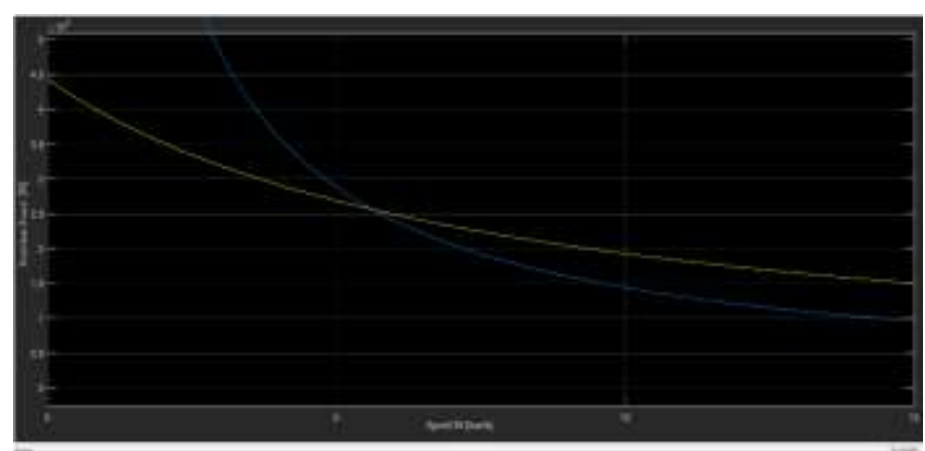

Fig. 13 Calculated traction curve for a high speed train for $\mathrm{km}=0,5$

We can notice that this curve do not show much consistency with the real conditions. In this case, if we examine the train configuration more precisely, we conclude that in the driven bogies (thus axes too) the verticle forces causes from only the weight of the traction motors, despite the fact that in the non-driven bogies they cause from the weight of the transformers and batteries which are heavier in total.Therefore verticle forces in the non-driven axles have to be substantially higher than the driven ones. If we revise $\mathrm{k}_{\mathrm{m}}$ value as 0,27 with a good approximation we obtain a new traction curve which is given below.

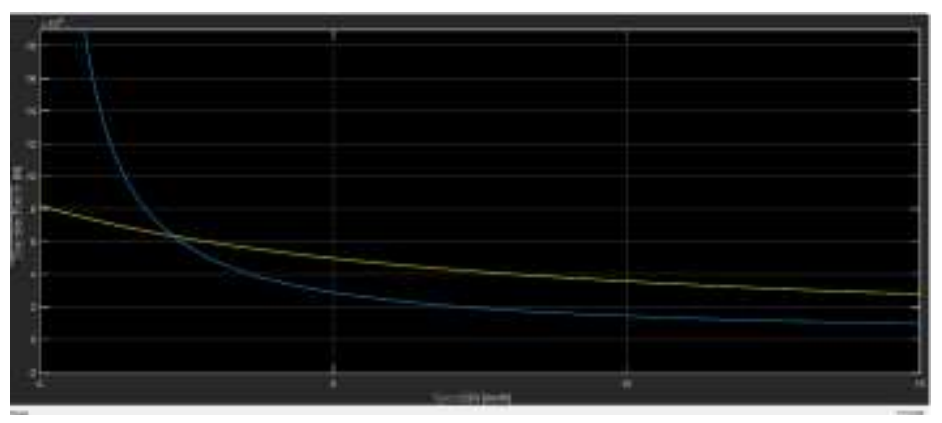

Fig. 14 Calculated traction curve for a high speed train for $\mathrm{km}=0,27$

If the obtained curve is examined carefully, it can be seen that it is consistent with a real high speed train curve. The obtained curve is compared with many of the similarly configurated high-speed trains and it has been seen that it is obvious the adopted approach in this study has given realistic outputs.

\section{Discussion \& CONCLUSIONS}

Calculation of the traction curve of a heavy haul shunting locomotive has been done according to relevant formulas. After the production stage, with the help of another heavy haul (mainline) locomotive, the maximum tractive effort and slip limit of the DE10000K is determined. The experimental results show that the proposed model is calculating maximum traction force and slip limit correctly. In the last chapter traction curve of a hypothetical high speed train is calculated and compared with heavy haul locomotives. It is proved that Curtiss-Kniffler formula is not valid for high speed trains. By means of taking into account the distributed traction power, calculating accurate slip curves are possible, and this is the key factor to determine the maximum allowed traction force of the high speed trains like any other railway vehicle. Beside 


\section{DOI: 10.17148/IARJSET.2021.8701}

we decide whether we use distributed traction power or not for any train set according to this results we also define how we will distribute the traction power. Hence, it is important to use the right formulas and understand the mathematics behind them. By adding the mathematical model of the traction system and road characteristics to the constructed model, the simulations can generalize to the real driving scenarios. It is planned in further studies. In this way, efficiency and performance analysis can be done for the determination of the specifications for both the vehicles and sub-systems used in the vehicles. These types of complex mathematical models can also be used as an input for improving the precision of the power system models used in energy efficiency studies.

\section{ACKNOWLEDGMENT}

I sincerely thank all of my teammates in TURASAS R\&D Department for their tremendous effort for making DE10000K locomotive project real. This was the one and only opportunity to make this study possible.

\section{REFERENCES}

[1] M. Sypiryagin, P. Wolfs, C. Cole, V. Spiryagin, Y. Q Sun, T. McSweeney, Design and Simulations of Heavy Haul Locomotives and Trains, London, 2017, CRC Press.

[2] O. Polach, "Influence of Locomotive Tractive Effort on the Forces Between Wheel and Rail”, Vehicle System Dynamics Supplement 35 pp. 7-22, 2001

[3] N. E. Boizumeau JR, P. Leguay, “Overview of braking energy recovery technologies in the public transport field,” 2011.

[4] Los Angeles County Metropolitan Transportation Authority, "Sustainable rail plan.” 2013.

[5] M. Miyatake and H. Ko, "Optimization of train speed profile for minimum energy consumption," IEEJ Trans. Electr. Electron. Eng., vol. 5, no. 3, pp. 263-269, 2010.

[6] M. Domínguez, A. P. Cucala, A. Fernández, R. R. Pecharromán, and J. Blanquer, "Energy efficiency on train control: design of metro ATO driving," in 9th World Congress on Railway Research WCRR 2011, 2011, pp. 1-12.

[7] U. Henning, F. Thoolen, J. Berndt, and A. Lohner, "Ultra low emission traction drive system for hybrid light rail vehicles," in SPEEDAM 2006. International Symposium on. IEEE, 2006, pp. 12-16.

[8] A. Onat, P. Votr, "Particle swarm optimization based parametrization of adhesion and creep force models for simulation and modelling of railway vehicle systems with traction", Simulation Modelling Practice and Theory, Volume 99, February 2020, 102026

[9] C. Urlu, "Demiryolu Araçlarının Illeri Dinamiği [Advanced Dynamics of Railway Vehicles]”, TCDD Press, Ankara, September 1999.

[10] Z. Tian, G. Zhang, N. Zhao, S. Hillmansen, P. Tricoli, C. Roberts, "Energy Evaluation for DC Railway Systems with Inverting Substations" IEEE International Conference on Electrical Systems for Aircraft, Railway, Ship Propulsion and Road Vehicles and International Transportation Electrification Conference, ESARS-ITEC 2018, 8607710, 2018.

[11] H. Deveci, "Dizel Elektrikli Lokomotiflerde Cer Sistemlerinin Gelişimi Üzerine Bir İnceleme”, Demiryolu Mühendisliği, vol:11, pp: 52-59 eISSN: 2687-2463, ISSN: 2149-1607 January 2020,

[12] M. Fleischer, "Traction Control for Railway Vehicles", ISSN 1437-675X

[13] A. Radosavljevic, "Determination of traction characteristics of diesel locomotives by least square method applied to experimental data" Transactions on Modelling and Simulation vol 21, 1999 WIT Press, www.witpress.com, ISSN 1743-355X

[14] F. Rick, R. Grimm, G. Venter, "Innovative method for measuring the tractive effort of rail vehicles", railway-research.org

[15] Ö. Akbayır, F.H Çakır, "Enerji Verimliliği İçin Tren Direnci Formüllerinin Karşılaştırılması" The Journal of Graduate School of Natural and Applied Sciences of Mehmet Akif Ersoy University Special Issue 1: 112-126 (2017)

[16] P. Lukaszewics, "Energy Consumption and Running Time for Trains (Ph.D Dissertation), Dept. of Vehicle Engineering, Royal Instute of Technology, Stockholm, 2001

[17] Z. Yang, Z. Yang, H. Xia, F. Lin, "Brake Voltage Following Control of Supercapacitor-Based Energy Storage Systems in Metro Considering Train Operation State", IEEE Trancsanctions on Industrial Electronics, vol. 65, no. 8, August 2018.

[18] A. Frilli, E. Melli, D. Nocciolini, L. Pugi, A. Rindi "Energetic optimization of regenerative braking for high speed railway systems," Energy Conversion and Management, vol. 129, pp. 200-215, October 2016.

\section{BIOGRAPHY}

Halil Deveci received the B.Sc. and M.Sc. degrees in electrical power engineering from Kocaeli University, Kocaeli, Turkey, in 2016 and 2019, respectively. Currently, he is a Ph.D. student at the İstanbul Technical University, İstanbul, Turkey. He is working as an R\&D Engineer in the Turkish Locomotive and Engine Industry Inc. since 2017. His research interests include electrical machines, electromagnetism, power electronics, as well as excitation systems, and dynamical modelling of railway vehicles. 